\title{
The Effectiveness of Educational Program Based On BASNEF Model on the Urban Taxi Drivers' Healthy Lifestyle
}

\begin{abstract}
Background and objective: More than one-third of deaths is caused by wrong social and personal lifestyle in the world. The present study aimed to find out the effect of education program based on the BASNEF model on healthy lifestyle of Konarak taxi drivers.

Materials and methods: Framework of this study was a quasi-experimental study. Data was collected by research-made questionnaire based on BASNEF Model structures. 160 taxi drivers of Konarak city were selected as samples by Multi-stage random sampling method and divided into case and control groups. Then educational sessions were performed in the case groups. The training materials used in educational Sessions were pamphlets. The intervention included 2 training sessions for 1 month. Both groups were followed for two months after the intervention to perform the post-test. The data were analyzed using SPSS 16 and descriptive and analytical tests (t-test, Pearson, and Chi Square) ( $p$ $<0.05)$.

Results: The mean score of knowledge, attitude, behavior and Enabling Factors increased significantly after intervention $(p<0.001)$. Physicians and health personnel were the most frequent of subjective norms.

Conclusion: Implementing educational intervention programs can increase the level of knowledge, attitude, and behavior of drivers regarding healthy lifestyle. Paper Type: Research Article.

Keywords: education, life Style, drivers, BASNEF Model, Kenarak.
\end{abstract}

Citation: Jadgal Kh. M., Alizade-Seiouki H., Lotfi-Mayen-Boulagh, B. \& Zareban I. The Effectiveness of Educational Program Based On BASNEF Model on the Urban Taxi Drivers' Healthy Lifestyle . Iran J Health Educ Health Promot. Summer 2016;4(2): 110-119.
KheirMohammad Jadgal

PhD Candidate in Health Promotion and Health Education, School of Health, Shahid Sadoughi University of Medical Sciences, Yazd, Iran

Hadi Alizade-Seiouki

MSc in Health Education, School of Health, Torbat Heydariyeh University of Medical Sciences, Torbat Heydariyeh, Iran

Behrooz Lotfi Mayen Boulagh MSc in Health Education, School of Health, Zahedan University of Medical Sciences (ZAUMS), Zahedan, Iran

Iraj Zareban

* PhD in Health Promotion and Health Education, Health Promotion Research Center, Zahedan University of Medical Sciences (ZAUMS), Zahedan, Iran (Corresponding Author) zareban@yahoo.com

Received: 09 August 2015 Accepted: 08 September 2016 


\section{تأثير برنامه آموزشى مبتنى بر الكَوى بزنف بر سبك زندكى سالم رانندكان تاكسيى درونشهرى}

خيرمحمد جد دانشجوى دكترى تخصصى آموزش بهداشت و ارتقاى

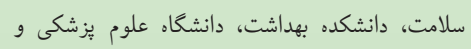
خدمات بهداشتى درمانى شهيد صدوقى يزد، يزد، ايران

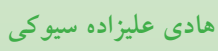

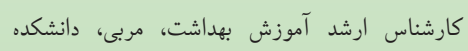

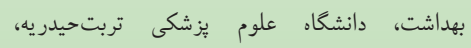
تربتحيدر يه، ايران

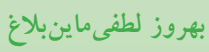
كارشناس ارشد آموزش بهداشت، دانشكده بهداشت، دانشكاء علوم يزّشكى زاهدان، زاهدان، ايران آندان ايرج ضاربان * دكترى تخصصى آموزش بهداشت، استاديار، مركز

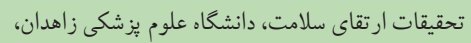
زاهدان، ايران (نويسنده مسئول) zareban@yahoo.com

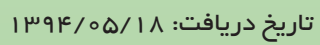

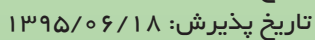

\section{0}

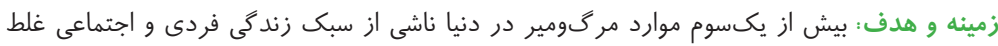

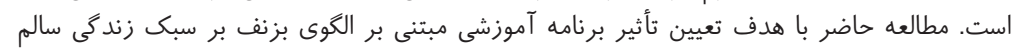

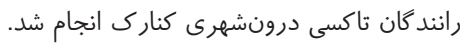

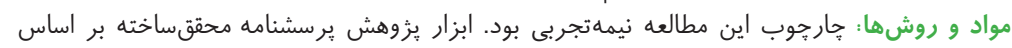

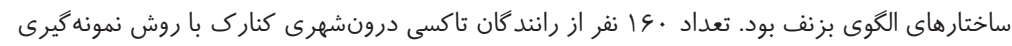

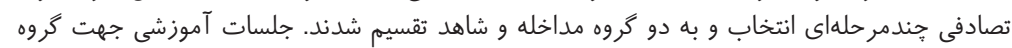

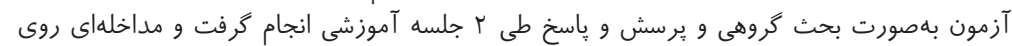

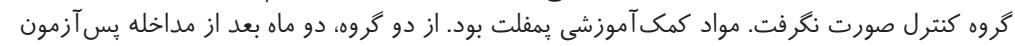

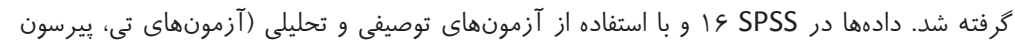

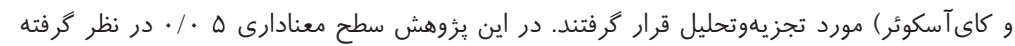

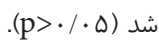

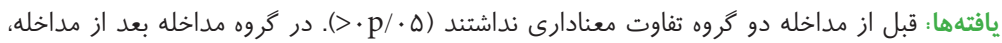

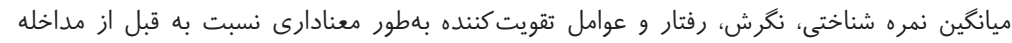

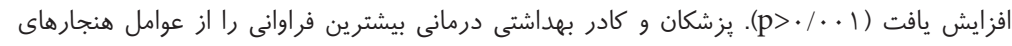
ذهنى تشكيل مى دادند.

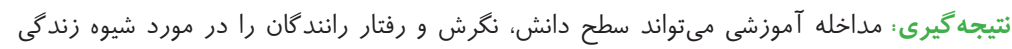

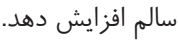
نوع مقاله : مطالعه يزوهشى.

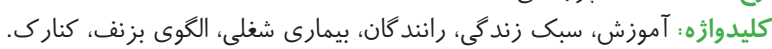

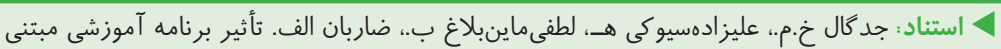

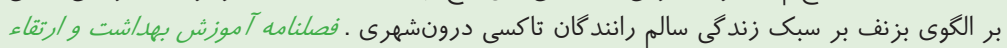

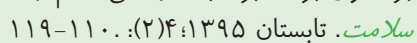


كارى نامنظم و فشرده، كمبودن زمان استر احت، اختلالات اسكلتى

و عضلانى مواجهه هستند (Y (I)؛ كه احتمال انجام رفتارهاى مغاير

سبك زندگى بخشى از زندگى است و شامل طيف كامل

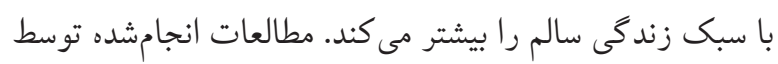

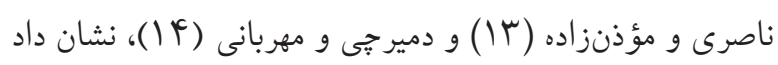

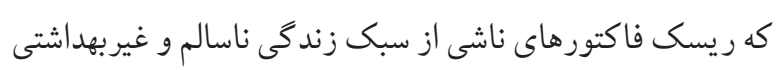
در رانند گان كشور ما شيوع بالايى دارد. در مطالعات اميرى و همكاران (ل| () و هزاوهاى و همكاران

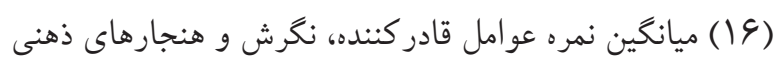

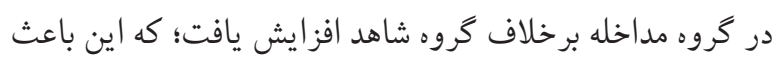

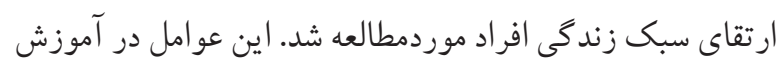
بهداشت تشكيلدهنده الكويى به نام بزنف هستند كه بهعنوان

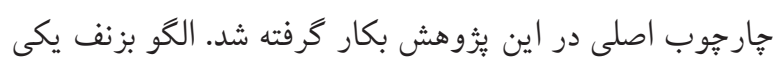

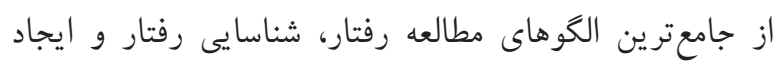

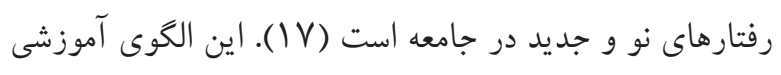
در تغييرات رفتارى به عواملى مانند نكرش (سازمانبندى نسبتاً دائمى باورها در مورد يك شئ يا موقعيت)، عوامل قادر كننده

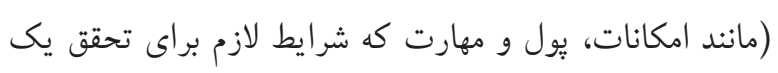

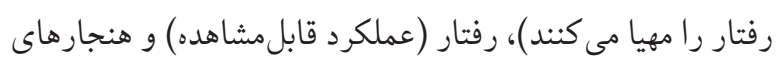
ذهنى (فشار اجتماعى دركشده كه بر اساس آن فرد از خواستههاى كسانى كه برايش مهمتر از بقيه هستند تبعيت مى نمايد) اشاره

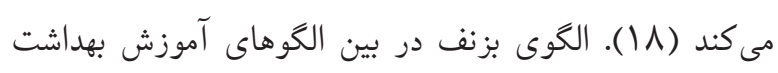
بلهنوعى يك الحوى اكتشافى و برنامهريزى جهت تغيير رفتار

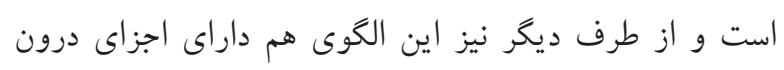
فردى و هم هنجارهاى اجتماعى مؤثر بر سبك زندگى مى باشد آند

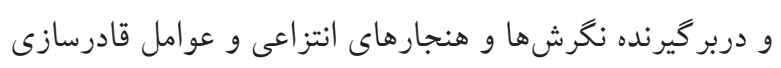
است. لذا اين مطالعه بر آن است كه از اين الكو استفاده نماييم.

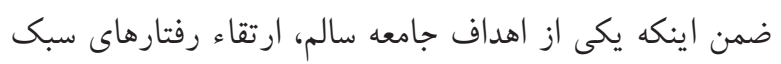

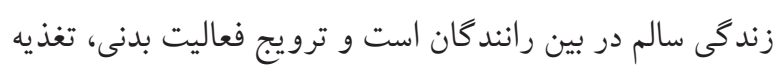

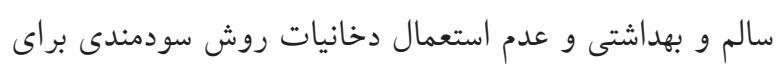

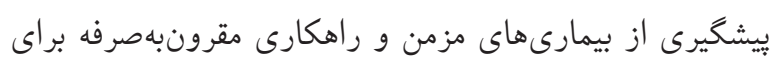

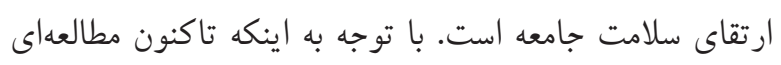

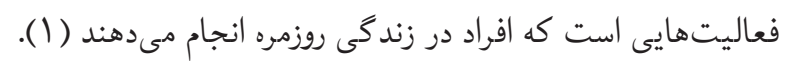

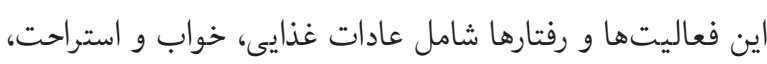

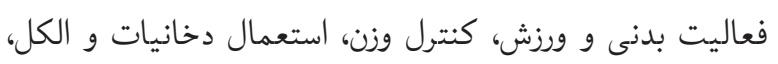

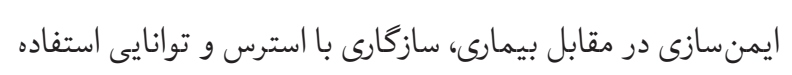
از حمايتهاى خانواده و جامعه است (T). امروزه اعتقاد بر اين

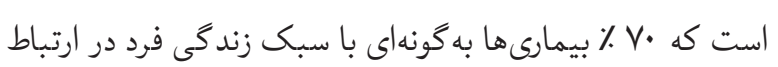

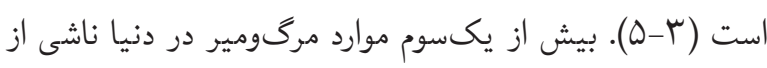

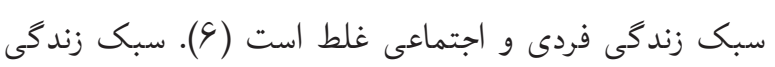
سالم و متعاقب آن تغذيه سالم و فعاليت بدنى، خطر بيمارى هاى وني

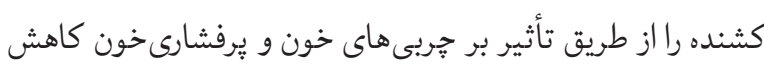

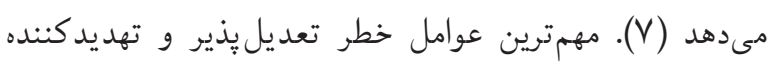
سلامتى عبارتاند از: برنامه غذايى ناسالم، كمتحركى و واستعمال دخانيات. اين عوامل از طريق عوامل خطر واسطهاى بيان

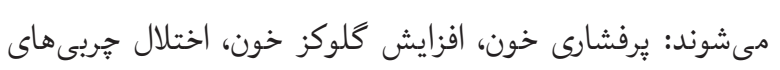
خون (بهويثه كلسترول LDL)، اضافهوزن و جاقى (^) (A). سازمان جهانى بهداشت در بيانيه اولين كنفرانس جهانى شيوه

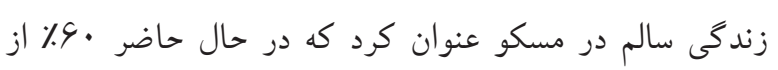

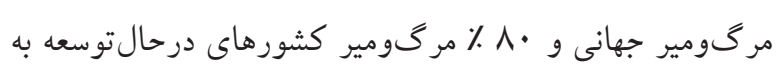

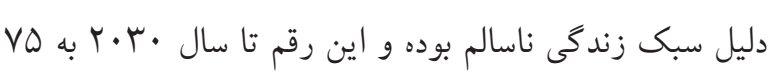

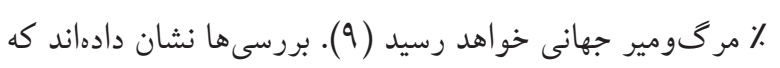

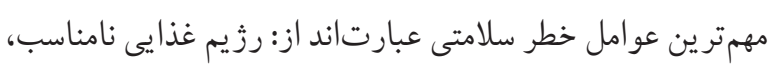

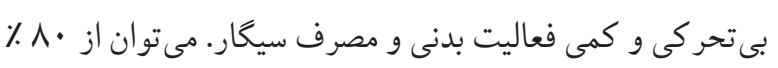

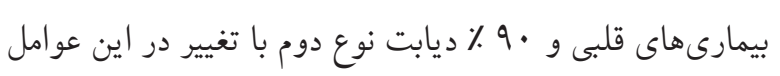

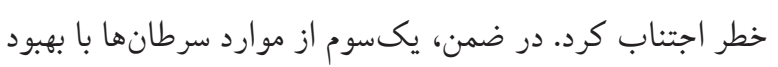

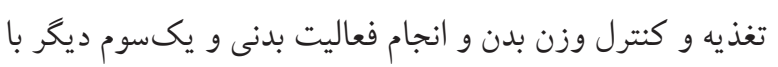

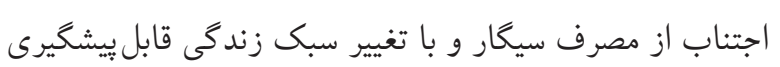
هستند (·) (1). شغل رانندگى نيز جزء مشاغل بدون تحرى طبقهبندى (له مىشود (11). راند كان علاوه بر استرسهاى شغلى با نوبتهاء 
با به گز ينه غلط امتياز ا تعلق مى گرفت و دامنه امتيازدهى بين

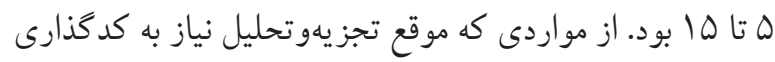

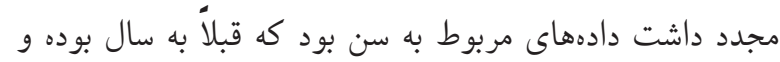

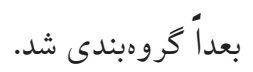

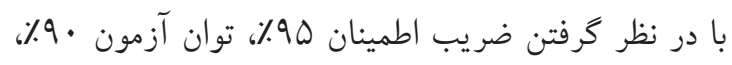
ميزان خطاى ه٪ و ميانكين و انحراف معيار مطالعه مشابه نصرآبادى و همكاران (19) در شهرستان زاهدان در خروهين

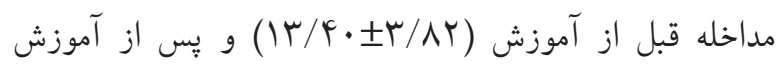

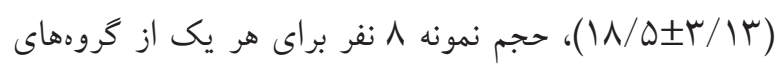

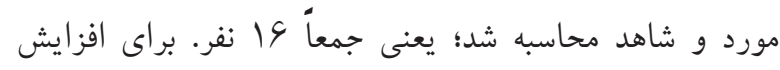
دقت مطالعه و همينطور به علت بسيار پايين بودن حجم نمونه بهدستآمده و ضرورت نياز به حجم نمونه بالاتر در كارهاى

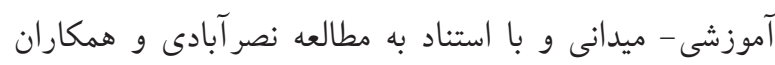

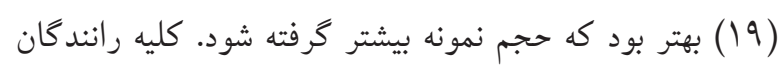

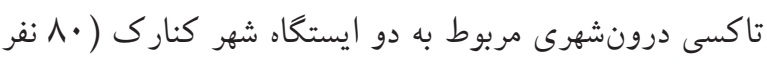

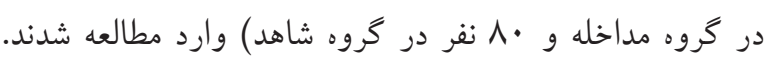

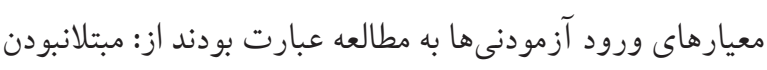

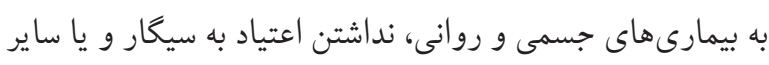

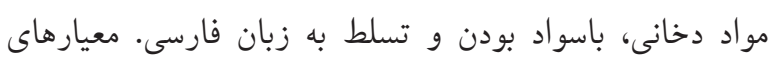

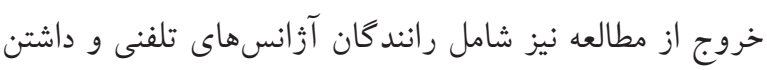
مشاغل ديكر بهغيراز رانندگى بودند. روش نمونه گيرى در اين مطالعه از نوع تصادفى جندمرحلهاى بردي

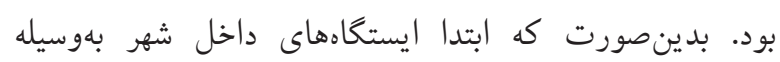
نقشه به دو بخش تقريباً مساوى شمالى و جنوبى تقسيم شدند؛ بند

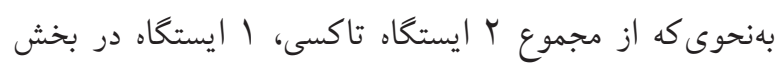

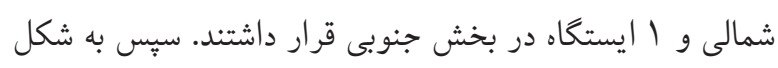
تصادفى ايستخاه بخش شمالى بهعنوان كروه شاهد و ايستخاه

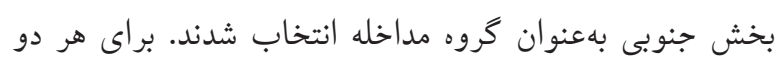

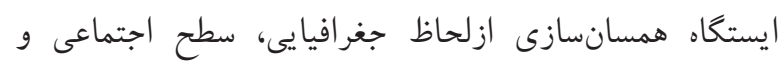

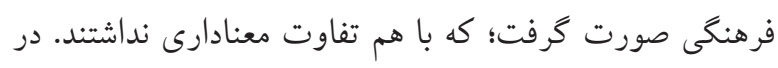

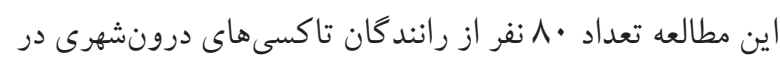

در اين زمينه در شهر كنارك انجامنشده بود، لذا مطالعه حاضر با

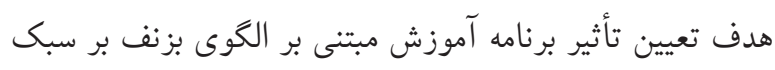

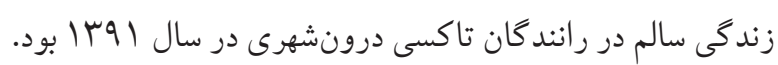

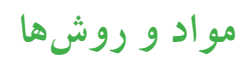
مطالعه حاضر يك مطالعه مداخلهاى نيمه تجربى، با كروههاى

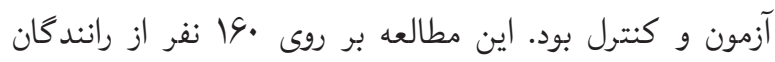
تاكسى درونشهوى كنارى در سال اوسا به اجرا درآمد. ابزار

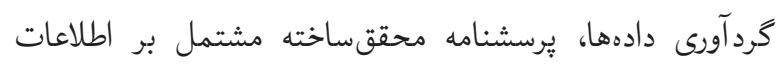

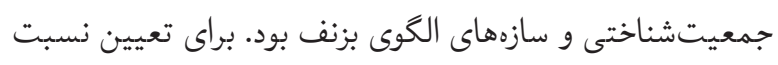

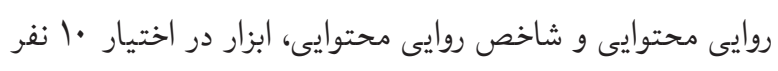

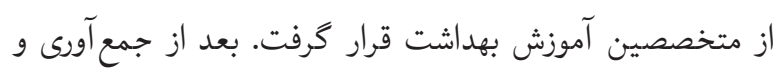

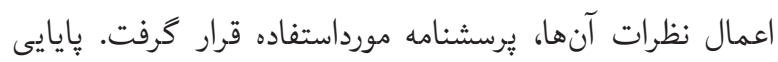

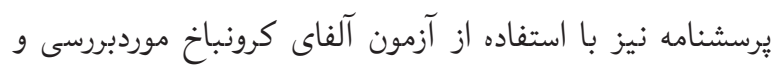

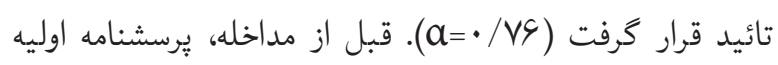

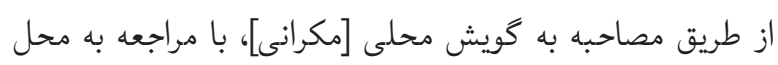

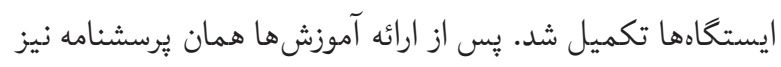
توسط گروههاى مداخله و شاهد تكميل و كد گذارى شدند.

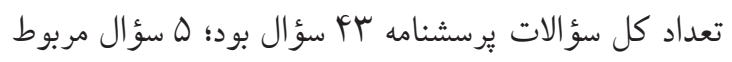

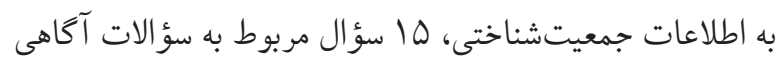
(4 سؤال فعاليت بدنى، 9 سؤال استعمال دخانيات و ب سؤال

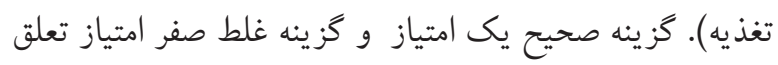
مى گرفت؛ دامنه امتيازدهى بين صفر تا ها بود. سؤالات نكرش ئه

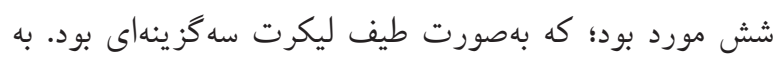
كزينه صحيح امتياز ب و به گزينه غلط امتياز ا تعلق مى گرفت

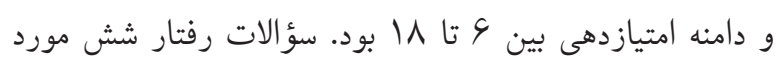

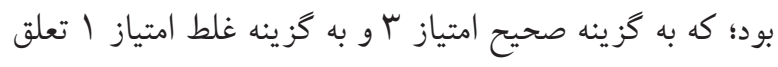

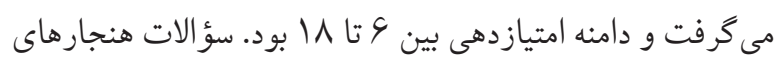

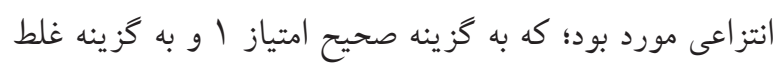
امتياز صفر تعلق مى گرفت و دامنه امتيازدهى بين · تا و بود. يبج سؤال مربوط به عوامل قادر كننده بود؛ كه به كزينه صحيح امتياز 
و كروه شاهد

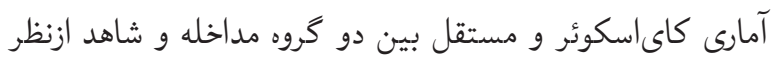
اطلاعات جمعيتشناختى (سن، سطح سواد، وضعيت تأهل، محل سكونت و سابقه كارى) اختلاف معنادارى مشاهده نشد

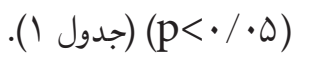

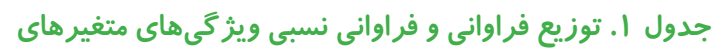
جمعيتشناختى راند كَان تاكسى درونشهرى درانى در دو كَروه مداخله و شاهد

\begin{tabular}{|c|c|c|c|c|c|c|c|}
\hline \multirow{2}{*}{ مقدار p } & \multirow{2}{*}{ آزمون } & \multicolumn{2}{|c|}{ شاهد } & \multicolumn{2}{|c|}{ مداخله } & \multirow{2}{*}{ جمعيتشناختى مشخصات } & \multirow{2}{*}{ جمعيتشناختى } \\
\hline & & درصد & تعداد & درصد & تعداد & & \\
\hline \multirow{5}{*}{$\cdot 109$} & \multirow{5}{*}{ مستقل } & 4 & $\Delta$ & 1. & $\wedge$ & $r \Delta-10$ & \multirow{5}{*}{ سن } \\
\hline & & FV & rV & r & ro & $r \Delta-r \Delta$ & \\
\hline & & ro & $r$. & rq & r & $F \Delta-r_{\Delta}$ & \\
\hline & & rt & 11 & ro & $r$. & $\Delta \Delta-F \Delta$ & \\
\hline & & . & . & $\Delta$ & r & $+\Delta \Delta$ & \\
\hline \multirow{2}{*}{$\cdot / \wedge \varsigma$} & \multirow{2}{*}{ كاى اسكوئر } & rq & rV & r & ro & مجرد & \multirow[b]{2}{*}{ وضعيت ازدواج } \\
\hline & & 94 & $\Delta r$ & 99 & $\Delta \Delta$ & متأهل & \\
\hline \multirow{4}{*}{. } & \multirow{4}{*}{ كاى اسكوئر } & r & rv & 19 & ir & بى سواد & \multirow{4}{*}{ سطح تحصيلات } \\
\hline & & ו & $\Delta$. & r & rs & خواندن و نوشتن & \\
\hline & & re & 01 & ro & rᄉ & زير دييلم & \\
\hline & & ir & 19 & if & 11 & دييلم & \\
\hline & & r & r & r & r & كاردانى و بالاتر & \\
\hline \multirow{2}{*}{$\cdot / V^{\mu}$} & \multirow{2}{*}{ كاى اسكوئر } & s9 & س & $\checkmark$. & $\Delta S$ & شهر & \multirow{2}{*}{ محل سكونت } \\
\hline & & rq & TV & $r$. & TF & روستا & \\
\hline \multirow{3}{*}{.$|4|$} & \multirow{3}{*}{ مستقل } & $\Delta \mu$ & er & $\Delta 9$ & iv & $1 \cdot-\Delta$ & \multirow{3}{*}{ سابقه كار } \\
\hline & & ro & $r \wedge$ & re & $r V$ & $10-1$. & \\
\hline & & Ir & 1. & $\checkmark$ & 4 & +10 & \\
\hline
\end{tabular}

جدول r مقايسه ميانگين و انحراف معيار نمره آكاهى، نكرش و عوامل تقويت كننده (فعاليت بدنى، استعمال دخانيات

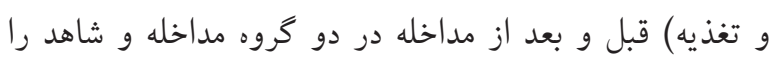
نشان مىدهد.
ايستخاه بخش شمالى طى دو جلسه آموزشى يكساعته (هر جلسه

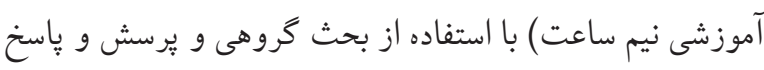

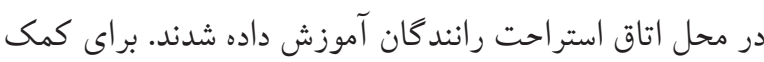

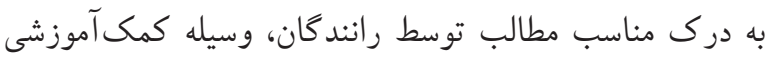

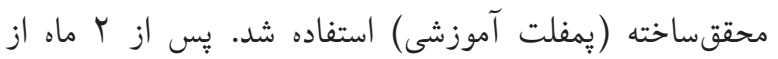

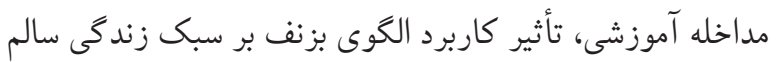
از طريق بس آزمون در دو گروه مداخله و شاهد سنجيده شد. با توجه به بررسىهاى اوليه صورت گرفته و توجيه افراد كروه دوره

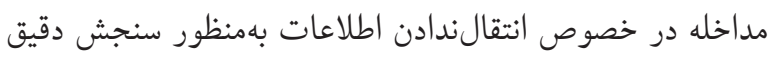
تأثير آموزش، احتمال ارائه مطالب آموزشى به يكديكر به حداقل

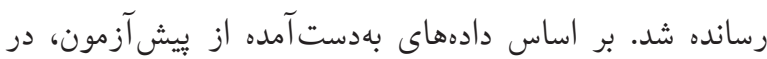

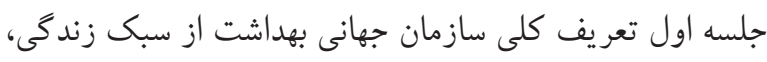

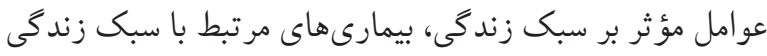

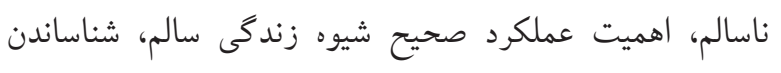

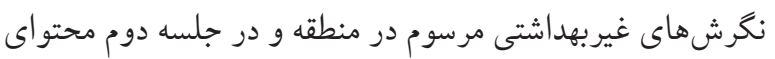
آموزشى بر اساس الكوى بزنف آموزش داده شد.

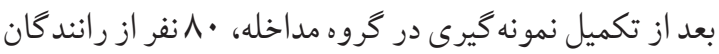

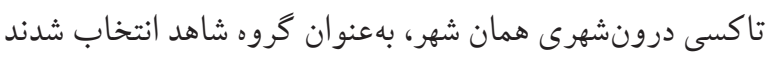

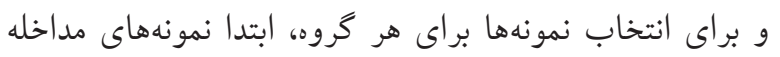

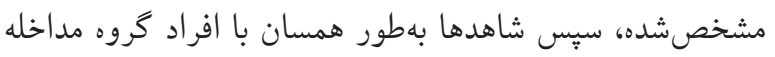
تعيين و وارد مطالعه شدند.

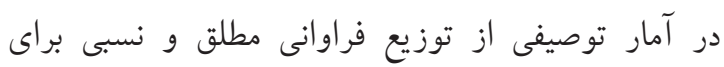

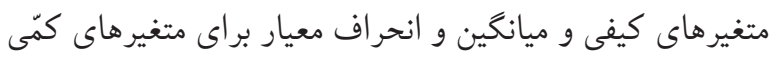

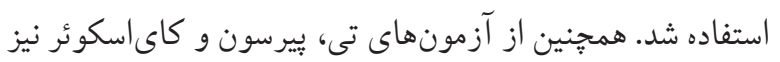
استفاده شد و تجزيهو تحليل دادهها با SPSS 19 انجام شد. تكميل يرسشنامه بهعنوان رضايت شركت كننده براى شر كت در مطالعه

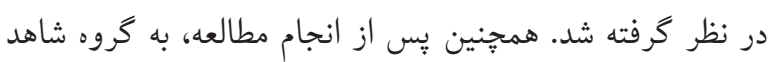
آموزش داده شد. يافتهاه ميانگين و انحراف معيار سنى گروه مداخله V• / 
جدول r. مقايسه ميانگين و انحراف معيار نمره آَّاهى، نگرش و عوامل تقويت كننده قبل و بعد از مداخله در دو گروه مداخله و شاهد

\begin{tabular}{|c|c|c|c|c|c|c|}
\hline \multirow[t]{2}{*}{ اختلاف } & \multirow{2}{*}{ آزمون زوجى } & بعد از مداخله & قبل از مداخله & \multirow{2}{*}{ كروه } & & \multirow{2}{*}{ متغير } \\
\hline & & ميانگين و انحراف & ميانگين و انحراف & & & \\
\hline $1 / 1 V \pm 1 / 01$ & $\leq \cdot / \cdots \cdot 1$ & $r / l \pm 1 / 4 r$ & $1 / 9 \mu \pm 1 / \cdot r$ & مداخله & \multirow{2}{*}{ فعاليت بدنى } & \multirow{9}{*}{ آكاهى } \\
\hline$. / \cdot G \pm \cdot / r F$ &.$/ I Y F$ & 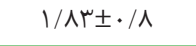 & 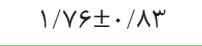 & شاهد & & \\
\hline $\mathrm{p} \leq \cdot / \cdots \cdot$ & & $\mathrm{p} \leq \cdot / \cdots 1$ & $\mathrm{p}=\cdot / r V \pi$ & & 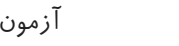 & \\
\hline $1 / r 1 \pm 1 / 4 q$ & $\leq \cdot / \cdots \cdot 1$ & 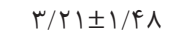 & $1 / 9 \pm \cdot / 94$ & مداخله & & \\
\hline$\cdot / \cdot r \pm \cdot / 10$ & .1109 & $1 / \wedge 1 \pm \cdot / \wedge \Lambda$ & 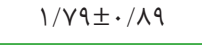 & شاهد & & \\
\hline $\mathrm{p} \leq \cdot / \cdots 1$ & & $\mathrm{p} \leq \cdot / \cdots 1$ & $\mathrm{p}=\cdot / \kappa \mu \wedge$ & & آزمون & \\
\hline$\cdot / \Delta \wedge \pm \cdot / \wedge \Delta$ & $\leq \cdot / \cdots \cdot 1$ & $1 / 9 \pm \cdot / 9 F$ & $1 / \cdot 1 \pm \cdot / 1$ & مداخله & \multirow{2}{*}{ تغذيه } & \\
\hline$\cdot / \cdot r \pm \cdot / 10$ & .1109 & $1 / \cdot F \pm \cdot / \wedge 1$ & $1 / \cdot 1 \pm \cdot / 1$ & شاهد & & \\
\hline $\mathrm{p} \leq \cdot / \cdots \cdot$ & & $\mathrm{p} \leq \cdot / \cdots 1$ & $\mathrm{p}=1 / \cdots$ & \multicolumn{2}{|c|}{ Inde آزمون } & \\
\hline $1 / r V \pm 1 / 9 r$ & $\leq \cdot / \cdots \cdot 1$ & $r / V F \pm 1 / q r$ & $r / \uparrow \& \pm 1 / \uparrow \Delta$ & مداخله & \multirow{2}{*}{ فعاليت بدنى } & \multirow{15}{*}{ ن نكرش } \\
\hline$\cdot / \cdot r \pm \cdot / 19$ & $\cdot / \cdot \wedge \mu$ & $r / \Delta s \pm 1 / \psi q$ & $r / \Delta \mu \pm 1 / \psi \wedge$ & شاهد & & \\
\hline $\mathrm{p} \leq \cdot / \cdots \cdot$ & & $\mathrm{p} \leq \cdot / \cdots 1$ & $\mathrm{p}=\cdot / \mathrm{\wedge} \wedge$ & & آآزمون & \\
\hline$\cdot / V Y \pm 1 / 1 r$ & $\leq \cdot / \cdots \cdot 1$ & $r / l f \pm 1 / r v$ & $r / F I \pm I / I V$ & مداخله & & \\
\hline$\cdot / \cdot r \pm \cdot / 10$ & .1109 & $r / \Gamma I \pm I / r \wedge$ & $r / r q \pm 1 / r \wedge$ & شاهد & & \\
\hline $\mathrm{p} \leq \cdot / \cdots \cdot$ & & $\mathrm{p} \leq \cdot / \cdots \cdot$ & $\mathrm{p}=\cdot / \Delta r r$ & & آز آزمون & \\
\hline 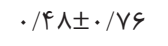 & $\leq \cdot / \cdots \cdot 1$ & $1 / V \wedge \pm \cdot / V \vee$ & $1 / r_{9 \pm \cdot / V q}$ & مداخله & \multirow{2}{*}{ تغذيه } & \\
\hline$. / \cdot r \pm . / 10$ & .1109 & $1 / \mu I \pm \cdot / V r$ & $\mid / r q \pm \cdot / V 1$ & شاهد & & \\
\hline $\mathrm{p} \leq \cdot / \cdots 1$ & & $\mathrm{p} \leq \cdot / \cdots 1$ & $\mathrm{p}=1 / \ldots$ & \multicolumn{2}{|c|}{ Inde آزمون } & \\
\hline$\cdot / \Lambda \pm 1 / \cdot r$ & $\leq . / \cdots 1$ & $r / r F \pm r / \cdot r$ & $r / F F \pm 1 / \wedge \varphi$ & مداخله & \multirow{2}{*}{ فعاليت بدنى } & \\
\hline$. / . r \pm . / 19$ & $\cdot / \cdot \wedge \mu$ & $\Gamma / \Delta 1 \pm 1 / \wedge \varphi$ & $\uparrow / \uparrow \wedge \pm 1 / \wedge \Delta$ & شاهد & & \\
\hline $\mathrm{p} \leq \cdot / \cdots 1$ & & $\mathrm{p}<\cdot / \cdot r$ & $\mathrm{p}=\cdot / 1 \wedge 99$ & \multicolumn{2}{|c|}{ آزمون Inde } & \\
\hline$\cdot / \varsigma^{\mu} \pm \cdot / V \mu$ & $\leq . / \cdots 1$ & $1 / 9 \pm \cdot / 9 \Lambda$ & $1 / r s \pm \cdot / \Delta r$ & مداخله & \multirow{2}{*}{ تغذيه } & \\
\hline$\cdot / \cdot \pm \cdot \cdot / \cdot$ &.$/ 109$ & $1 / r s \pm \cdot / \Delta r$ & $1 / r G \pm \cdot / \Delta r$ & شاهد & & \\
\hline $\mathrm{p} \leq . / \ldots 1$ & & $\mathrm{p} \leq . / \cdots 1$ & $\mathrm{p}=1 / \cdots$ & & آزمون & \\
\hline
\end{tabular}


تغييرات نمره عوامل تقويت كننده تفاوت معنادارى نداشتند $\cdot(\mathrm{p}>\cdot / \cdot \Delta)$

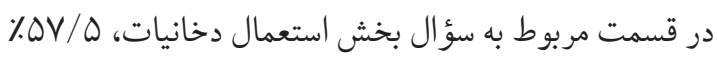

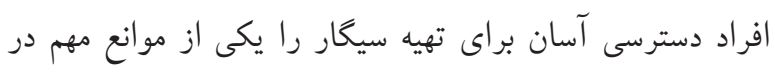

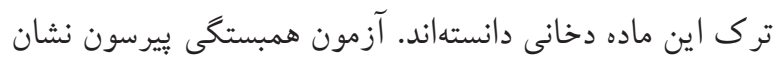

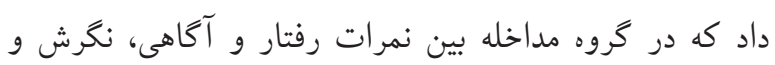

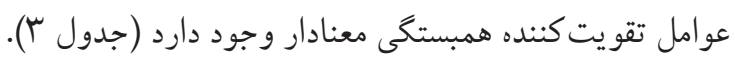
جدول س. آزمون همبستگى ييرسون بين نمرات رفتار، آكاهى، نخخر ش و عوامل تقويت كننده

\begin{tabular}{|c|c|c|}
\hline \multicolumn{3}{|c|}{ كروه مداخله } \\
\hline ضر يب همبستكى بييرسون & p-value & سازهها \\
\hline$\cdot / r \Delta \varphi$ & $\cdot / \cdot Y Y$ & آكاهى \\
\hline • $/$ TAT & $\cdot 1 \cdot \cdot 1$ & نكَرش \\
\hline 莎 & $\cdot 1 \cdot .1$ & عوامل تقويت كننده \\
\hline
\end{tabular}

بִ

بر اساس يافتههاى اين يُزوهش، مداخله آموزشى بر سبك زندگى

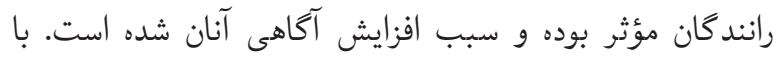
توجه به يايين بودن سطح آكاهى افراد در آغاز مطالعه، آكاهى

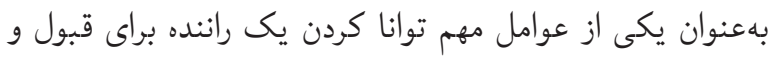

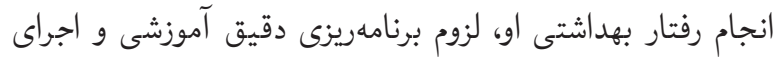
مداخلات بهمنظور ارتقاء سطح آحاهى مطرح مى شود. يافتهها

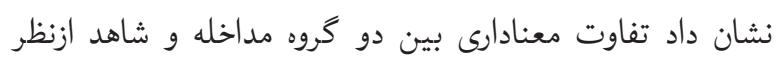
ميانكين آكاهى در سه بخش فعاليت بدنى، تغذيه و استعمال

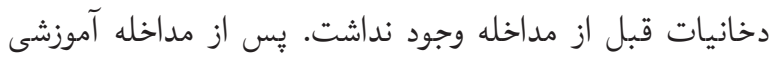
ميانكين نمرات گروه شاهد ازنظر آمارى تفاوت معنادارى نشان

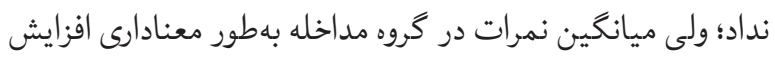

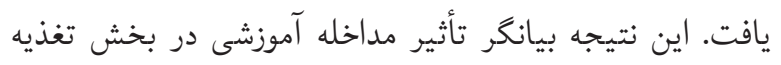

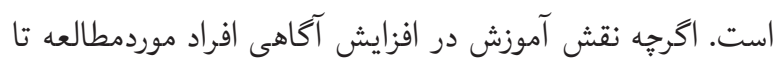

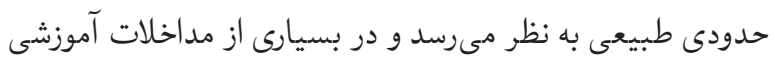

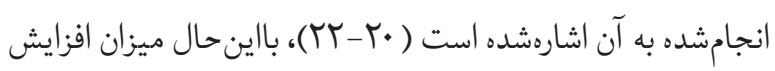

همانطور كه جدول r نشان مىدهد با توجه به ميانگين تغييرات نمره كسبشده در كروه مداخله و شاهد و با استناد به به به به به

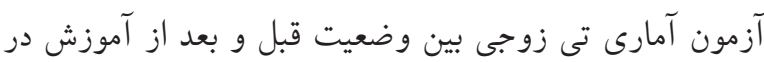

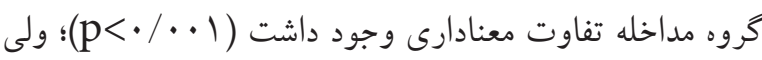

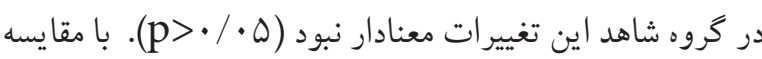
بين وضعيت قبل و بعد از مداخله در گروه مداخله و شاهد، آزمون

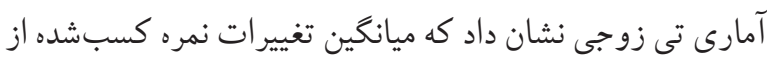

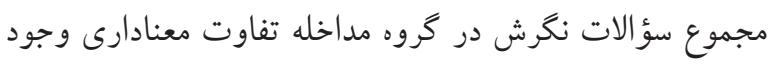

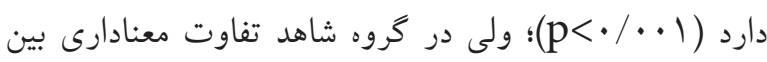

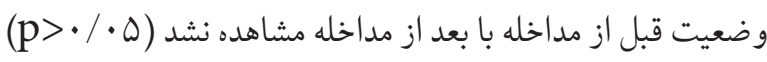

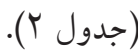
با استناد به آزمون آمارى تى زوجى و با مقايسه ميانگين

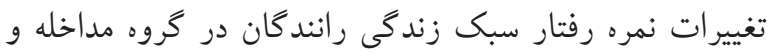
شاهد بين وضعيت قبل و بعد از مداخله، تفاوت معنادارى بين

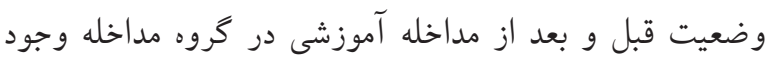

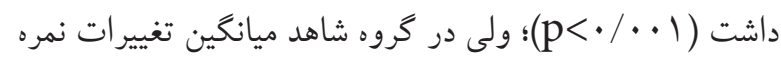
رفتار در بخشهاى فعاليت بدنى، استعمال دخانيات و تغذيه دروليه

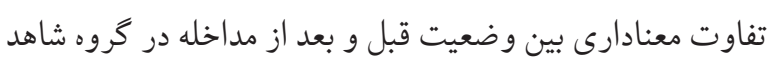

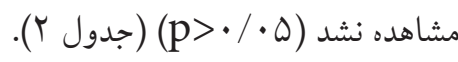

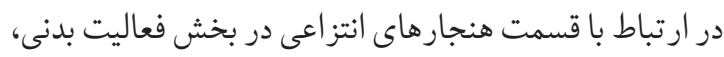

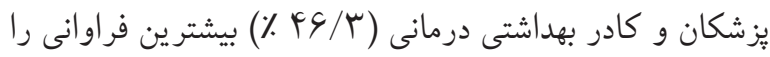

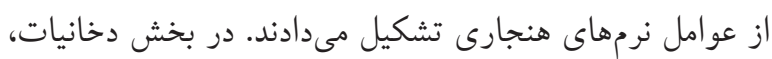

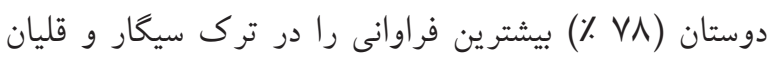
داشتهاند. در بخش تغذيه نيز، افراد اظهار داشتهاند كه بز شكان

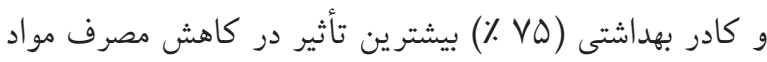
قندى افراد داشتهاند. ميانگين تغييرات نمره عوامل تقويت كننده با توجه به جدول

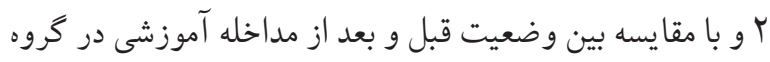

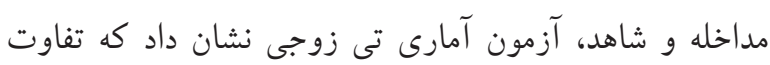
معنادارى در گروه مداخله بين وضعيت قبل و بعد از مداخله

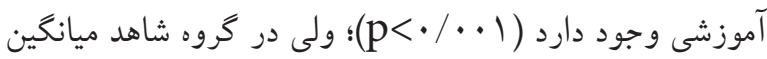


مطالعات مختلف نشان داده است كه يزشكان و كادر بهداشتى نقش مهمى در رفتارهاى تغذيهاى افراد موردبررسى داشتهاند ( $($ ( . $) 1)$

عوامل قادركننده در مطالعه حاضر شامل اطلاعات، مهارتهاى فعاليت بدنى، تغذيهاى و ساير مواردى كه در كروه مداخله سبب هدايت قصد رانند گان به انجام رفتارهاى مربوط به فعاليت بدنى، مهارتهاى نكشيدن دخانيات و عادات تغذيهاى مناسب موردنظر محققين بود مىشد. يس از مداخله آموزشى افزايش معنادارى در ميانگين نمره عوامل قادركننده در دو بخش ست ستري فعاليت بدنى و تغذيه در گروه مداخله ديده شد. در بسيارى از

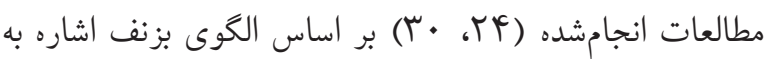
نقش منحصربهفرد عوامل قادركننده در تبديل قصد رفتارى به رفتار بهداشتى نمودهاند.

در قسمت مربوط به استعمال دخانيات ه/OV/ افراد بعد از مداخله آموزشى، دسترسى آسان براى تهيه سيگار را يكى از عوامل مهم در ترك اين ماده دخانى دانستهاند. از آنجايى كه در مقايسه با ساير مواد دخانى، سيخار بهظاهر سادهترين و ارزانترين مادهاى است كه بهراحتى در دسترس عموم افراد جامعه قرار دارد، شايد اين دليلى بر افزايش گرايش افراد جامعه بخصوص جوانان نسبت به استعمال اين ماده باشد. مطالعه انجامشده توسط اميرى و همكاران (ه (1)، كه تأثير آموزش بر اساس الكوى بزنف بر سبك زندگى راندگان تاكسى شهر لنگرود را سنجيدهاند، يافتهاى مربوط به اين بخش را تائيد مى كند. مشكلات رانندگان جهت شركت در كلاسهاى آموزشى عليرغم تمايل آنها و فشرده بودن جلسات آموزشى از محدوديتهاى مطالعه حاضر بود. كه سعى شد با به حداقل رساندن تعداد جلسات (بهجاى آموزشدادن كروه • ب نفره از

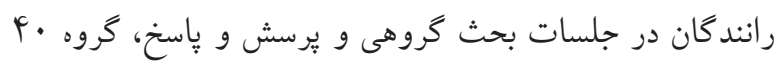
نفره آموزش داده شدند) تا حدودى اين محدوديت برطرف شد.

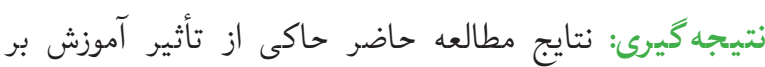
اساس سازهاى الكوى بزنف بر ارتقاء رفتارهاى سبك زندگى در
و ارتقاء آكاهى در مداخلات آموزشى نكتهاى قابل توجه است. بر اساس يافتهاى اين يزوهش در گروه مداخله ميانگين تغييرات نمره نگرش كسبشده در بخش فعاليت بدنى

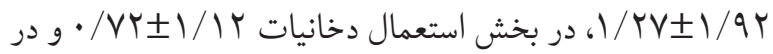

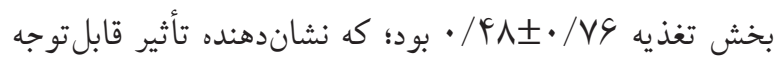
آموزش در بهبود نكرش رانندگان در مورد سبك زندگى سالم در سه بخش فعاليت بدنى، استعمال دخانيات و تغذيه است. مطالعات زيادى كه در اين زمينه صورت گرفته است با يافتههاى اين يثوهش مشابهت و همسوئى دارند (YT-YY). در اين مطالعه، رفتار بهطور معنادارى گيس از آموزش ارتقا يافت. بهطورى كه ميانگين تغييرات نمره رفتار سبك زندگى

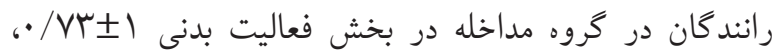
در بخش استعمال دخانيات •| / / / / • و در بخش تغذيه 1/9士1/FV ارتقاء رفتارهايى از قبيل انجام فعاليت بدنى، اجتناب از كشيدن قليان و همجنين اجتناب از خوردن غذاهاى آماده و سرخ كردنى و بهطوركلى تغذيه سالم در بين اين گروه مىباشد. ارتقاء رفتار بعد از مداخلات آموزشى، در مطالعات متعددى مشاهدهشده است

با توجه به نتايج يزوهش، در بخش فعاليت بدنى، يزشكان و كادر بهداشتى درمانى ( ( نرمهاى هنجارى تشكيل مىدادند؛ كه اين نتايج با يزوهش شريفىراد و عزيز (YV) همخوانى دارد. در بخش استعمال دخانيات، دوستان (VA ٪)، بيشتر ين فراوانى را در ترك سيگار و قليان داشتهاند. به نظر مىرسد بالا بودن اين درصدها در مطالعه حاضر نشانگر افزايش نقش اين عوامل در رفتار فعاليت بدنى و اجتناب از استعمال دخانيات باشد. مطالعه شريفىراد و عزيز

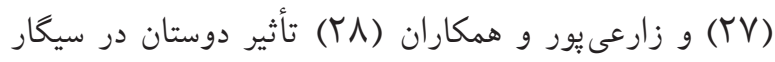
كشيدن را به اثبات رساندهاند. همجنين در بخش تغذيه، يزشكان و كادر بهداشتى (VD٪)، بيشترين تأثير در كاهش مصرف مواد قندى افراد داشتهاند. 
رانند گان باشيم. به علت وجود قوميت خاص در منطقه، استفاده از

زبان محلى كه در اين يزوهش نيز استفاده شد، بهعنوان يك اقدام

$$
\text { لازم و مفيد ييشنهاد مى شود. }
$$

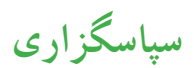

از كليه رانند گان تاكسىهاى درونشهرى كنارى و ساير كسانى

كه در اجراى اين يُوهش همكارى داشتهاند صميمانه تشكر و

$$
\text { قدردانى مىشود. }
$$

\section{References:}

1. Mazloomy Mahmoodabad, S.S., et al., The effect of social class on the amount of salt intake in patients with hypertension. Blood pressure, 2016: p. 1-4.

2. Huynen M, Martens P, Hilderink HBM. The Health impacts of globalization: a conceptual framework. Globalization and Health 2005; 3: 14

3. Behdani F, Sargolzaei MR, Ghorbani E. Study of the Relationship between Lifestyle and Prevelance of The Depression And Anxiety In The Students Of Sabzevar Universities. Asrar Journal 2000; No 2: Pages 27- 38. [Persian]

4. Moher M. Evidence of the effectiveness of intervention for secondary prevention and treatment of coronary heart (Dissertation). San Diego State University; 2001.

5. Edlin G, Golanty E. Health and Wellness. 8th ed. Boston: Jones and Bartlet; 2004.

6. WHO. The world health report 2002 - Reducing Risks, Promoting Healthy Life. Geneva: World health report 2002 press kit; 2002.

7. WHO. Diet, physical activity and health. Fifty-fifth World Health Assembly, Provisional agenda item 13.11; 2002.

8. WHO- Public Health Agency of Canada. Prevention of chronic disease: A Vital Investment, Tehran: seda; 2009.

9. WHO. First Global Ministerial Conference on Healthy Lifestyles and Non communicable Disease Control. 2011; Available at URL: http://www.who.int/nmh/events/ moscow_ncds_2011/conference_documents/Moscow declaration_en.pdf. Accessed April 2011.

10. Mansoorian M, Qorbani M, Shafieyan N, Asayesh H, Rahimzadeh Barzaki $\mathrm{H}$, Shafieyan Z, et al. Association between life style and hypertension in rural population of Gorgan. Journal of health promotion management. 2012; 1 (2): 23-28. [in Persian]

11. Hajamini Z, Cheraghalipour Z, Ebadi A, Azad Marzabadi E, Norouzi Koushali A. Comparison of job stress in military and non-military drivers in Tehran city. Ir J Military
بين رانند گان بود. آكاهى، نكرش، رفتار و تمام سازههاى الكوى بزنف يس از مداخله در گروه مداخله تفاوت معنادارى داشت و

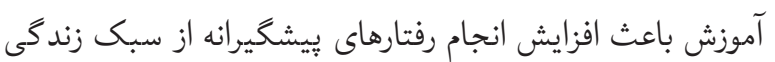
ناسالم شده بود. بر اين اساس، درصورتى كه اهداف و برنامهها بر روى آحاهى، نكرش و همجتينين عوامل قادركننده (هزينه، وقت و دسترسى آسان) در سه حيطه تغذيه، فعاليت بدنى و استعمال دخانيات در رانند گان بهطور جدىتر تمركز يابد ،مىتوانيم شاهد افزايش در ارتقاء رفتارهاى مرتبط با سبك زندكى سالم در

Medicine 2011; 13, (1): 25-30. [Persian]

12. Vakili M, Eslami Farsani SH, Hosseini S.M.H, Dehghani Tafti M.H. Prevalence of depression and its related factors among truck drivers in Yazd Province. 2010; Iran Occupational Health, 6 (4): 66-74.

13. Nasri $H$, Moazenzadeh M. Coronary artery disease risk factors in driving versus other occupations. ARYA Journal 2006; 2(2): 8-75. [Persian]

14. Demirchee A, Mehrabani J. Prevalence of obesity, overweight and hypertension and associated risk factors in adult men. Olympic fall 2010; 17: 87-103. [Persian]

15. Amiri A, Rkhshany F, Farmanbar R. The Effect of Educational Program based on BASNEF Model on Healthy Lifestyle of Taxi Drivers in Langroud. Journal of Torbat Medical Sciences 2013; 4 (1): 45-54. [Persian]

16. Hazavehei MM, Khani Jyhouni A, Hasanzadeh A, Rashidi $M$. The effect of educational program based on BASNEF model on diabetic (Type II) eyes care in Kazemi's clinic, (Shiraz). Iranian Journal of Endocrinology \& Metabolism 2008; 10 (2): 145-154.

17. Ebadifard Azar F, Solhi M, Roudbari M, Sadeghi A. Survey the Effect of Educational Intervention through the BASNEF Model on Preventive Behaviors According to Mental Health in Girl Adolescents. Journal of Guilan University of Medical Sciences 2009; 73: 20-29. [Persian]

18. Zarei, F., \& Taghdisi MH, S. M., Tehrani H, Shojayizade D. (2012). The Effect of Educational Intervention Based on BASNEF Model to Improve Interpersonal Communication Skills of Nurses. Journal of Alborz Health, 1(3), 173-178.. [Persian]

19. Nasrabadi T, Goodarzi Zadeh N, Shahrjerdi A, Hamta A. The Effect of Education on Life Style among Patients Suffering from Ischemic Heart Disease. J Mazandaran Univ Med Sci. 2010; 20 (79): 72-79. [Persian]

20. Hazavehei M, Asadi Z, Hassanzadeh A, Shekarchizadeh P. Comparing the effect of two methods of presenting physical education $\Pi$ course on the attitudes and practices 
of female students towards regular physical activity in Isfahan university of medical sciences. Journal of Medical Education. 2008; 8(1): 121-131. [Persian]

21. Rezaei N, Tahbaz F, Kimiagar M, and Alavi Majd H. Effect of nutrition education on knowledge, attitude, and practice of type 1 diabetic patients in Aligoodarz. Journal of Shahrekord University of Medical Sciences 2006; 8 (2): 52-59. [Persian]

22. Hazavehei SMM, Sharifirad GhR, Kargar M. The Comparison of Educational Intervention Effect Using BASNEF and Classic Models on Improving Assertion Skill Level. J Res Health Sci 2008; 8 (1): 1-11.

23. Baghyani-Moghadam MH, Shafiei F, Haydarneia AR, Afkhami M. Efficacy of BASNEF Model in Controlling of Diabetic Patients in the City of Yazd, Iran. Indian Journal of Community Medicine 2005; 30 (4): 10 -12.

24. Bantle JP, Wylie-Rosett J, Albraight AL, et al. Nutrition Recommendations and Interventions for Diabetes-2006. Diabetes care 2006; 29: 2140-2157.

25. Goldost F, Ebadifard F, Solhi M, The effect stress management training based on BASNEF model on behavior promotion multiple sclerosis patients, Hormozgan Medical
Journal, 2012; 16(4): 325-332. [Persian]

26. Jadgal Kh M, Nakhaei-Moghadam T, Alizadeh-Seiouki H, Zareban Ir, Sharifi-Rad J. Impact of Educational Intervention on Patients Behavior with Smear-positive Pulmonary Tuberculosis: A Study Using the Health Belief Model. Mater Sociomed. 2015; 27(4): 229-233

27. Sharifi Rad G, Aziz A. Effective factors on smoking behavior based on BASNEF model in dorm students of Isfahan University of Medical Sciences. Med J Hormozgan 2008; 4(11): 71-267. [Persian]

28. Zareipour M, Sadeghi R, Sadeghi Tabatabaei S, Seyedi $S$. effective factors on smoking based on BASNEF model in male students in Tehran medical sciences university. Journal of Urmia Nursing and Midwifery. 2011; 9 (1): 2329. [Persian]

29. Sharifirad G, Entezari MH, Kamran A, Azadbakht L. The effectiveness of nutritional education on the knowledge of diabetic patients using the health belief model. JRMS 2008; 14 (1): 1-6.

30. Glanz K, Rimer B, Lewis FM. Health behavior and Health education Theory, Research and Practice. 4thed San Francisco. Jossey-Bass publisher; 2008. 